\title{
Kidney Injury Molecule as A Urinary Biomarker in Kidney Injury in Critically Il Infants
}

\author{
E.A.Nawar, A.E.Elsadek, O.M.Abdel Haie and S.A.Nazem
}

Pediatrics Dept., Faculty of Medicine, Benha Univ., Benha, Egypt

E-Mail: siham01060421524@gmail.com

\begin{abstract}
Kidney injury (KI) is a major contributor toward infants mortality and morbidity and is associated with greater long-term risk of chronic kidney disease. The current diagnostic approach of KI is based on an acute decrease of GFR, as reflected by an acute rise in serum creatinine ( $\mathrm{SCr}$ ) levels and/or a decline in urine output over a given time interval, Recently several biomarkers have been proposed for the diagnosis of KI and these are in various stages of development and validation. to evaluate kidney injury molecule (KIM) as an early urinary marker for prediction of acute renal injury in infants.a comparative cross sectional study was performed on 2 groups: cases group included 30 critically ill infants who were suffering from a variety of critical conditions with mean age $6 \pm 2.1$ months, their sex distribution was $40 \%$ males and $60 \%$ females. Another group (control group) of 20 healthy control subjects matched the first group in age and gender. The time period of this study was between august 2016 to august 2017. All patients were subjected to complete maternal history taking, full clinical examination and laboratory investigations including CBC, CRP, Na, K, cord PH, Urea and serum creatinine were measured since the first $24 \mathrm{hrs}$ (1st sample) of admission and serum creatinine was repeated after $48 \mathrm{~h}$ of admission (2nd sample). Critically ill infants were sub sequently discriminated ,within 48 hour of admission ,according to the criteria proposed by the AKIN ,into neonates with KI (group 1A) and infants without KI (group $1 \mathrm{~B}$ ), Comparative data were collected between first and second samples of hematologic investigations, renal functions , $\mathrm{Na}, \mathrm{K}$, cord $\mathrm{pH}, \mathrm{CRP}$ and blood culture growth in all studied critically ill infants, cases without KI and cases with AK. Another comparison of KIM, creatinine was done between first and second samples in all studied critically ill infants , with KI and without KI. It was revealed predominance of female sex with no significant difference between groups of the study regarding age, length, and weight. No significant differences were found in hematologic investigations, renal functions, $\mathrm{Na}, \mathrm{K}$ or blood culture growth at diagnosis between cases and controls as well as between critically ill infants with and without KI. It was reported significant change in creatinine level in second sample between KI patients and patients without KI and also it was revealed significant increase in KIM concentration in first sample. As well as KIM level was significantly higher in second when compared to first sample in critically ill patients with KI. KIM is a sensitive urinary biomarker in early detection of KI in infants.
\end{abstract}

Keywords: Acute kidney injury (AKI), kidney injury molecule (KIM-1),Complete blood count (CBC), C-reactive protein (CRP), Glomerular filtration rate (GFR), Acute kidney injury network (AKIN), (AUC) area under ROC curve , Receiver operating characteristic curve (ROC).

\section{Introduction}

Kidney damage (KI) Previously, babies is intricate issue that fails to offer a uniform presentation [15].

Clinical indications suggesting ki happen late, yet the pathology might rapidly Advance should intense renal disappointment. Presently those analysis from claiming ki is dependent upon those expanded levels from claiming serum creatinine utilizing serial estimations furthermore on oliguria [1].

Those promptly analysis from claiming ki will be vital in the start from claiming therapy; however, the evaluation about diminished kidney work on the support for serial creatinine estimations is deferred [13].

Serum creatinine as a utilitarian kidney marker doesn't show kidney tissue injury; it best measures the amassing of the endogenous marker Concerning illustration an outcome of diminished glomerular filtration rate (GFR). [13].

On account of the occurrence of ki may be at present secondary and the result stays poor, researches have kept tabs looking into identikit new biomarkers fit to suspect the $\mathrm{ki}$ analysis in hours alternately much times When a pee yield decrease or SCr. Augment might be distinguished. Promptly ki analysis might bring out new perspectives Previously, restorative possibilities. Moreover, the information of novel serum Also pee biomarkers might transform those methodology to ki Furthermore camwood assistance will separate the middle of distinctive reason for made ki What's more actualizing preventive intercessions [2].

New markers for KI, for example, NGAL (neutrophil gelatinase-associated lipocalin), KIM-1 (kidney harm atom 1), and IL-18 (interleukin 18), assessed both done serum or urine, have favorable element over serum creatinine Eventually Tom's perusing straightforwardly reflecting damage of the kidney. NGAL, known as lipocalin 2, Furthermore at first portrayed Concerning illustration a oncogene communicated by numerous mankind's cells, including epithelial phones Also neutrophils [3].

KIM-1 may be very nearly only communicated on the apical surface of proximal tubule units Similarly as An light of injury, and its outflow doesn't vanish until those harm is completely determined [ 8].

\section{Subject and methods}

This case controlled study was conducted on 30 critically ill infants of both sex admitted to pediatric Intensive Care Unit (PICU) of Baha university hospital. And 20 healthy infants matching the first group in age, sex as a control group. The study was conducted during the period from August 2016 to August 2017.Two samples of blood and urine were obtained day of admission and 48 hours later. Informed consents were taken from the parents of the included infants. The study was approved by the ethical committee of Banha University. Laboratory study was done in Clinical Pathology Department at Benha University.

\subsection{Inclusion Criteria}

All children who are critically ill treated in the PICU aged from 1 month to 23 months .Critically ill defined as use 
of mechanical ventilation, hemodynamic instability or requiring resuscitation or inotropic drugs and admitted to PICU during the study period [7].

\subsection{Exclusion Criteria}

Children with renal insufficiency (nephrotic syndrome, nephritic syndrome), patients who received hemodialysis, congenital kidney disease, auto immune disease related to kidney, renal malignancy.

The infants were enrolled into two groups:

Group (1) study group:

30 critically ill infants who were at risk to develop kidney injury (KI).

Group (2) control group:

The control group including 20 infants, apparently healthy with age and weight matched with the patient group with no evidence of major illness.

\section{Methods}

- History taking covering all aspects.

- Clinical Examination to whole body.

- Laboratory Investigation

\section{Sample collection}

- $1 \mathrm{ml}$ of heparinized sterile arterial blood was taken for ABG and was done using 9180 Electrolyte Analyzer.
- $2 \mathrm{ml}$ of blood was taken on ethylene diamine tetra-acetic salt $(1.2 \mathrm{mg} / \mathrm{mL})$ as an anticoagulant, then was used for complete blood count (CBC) Done by automated hematology analyzer sysmex xs 800 (SN:63387).

- Two ml of blood was taken on sodium citrate, as an anticoagulant and was used for measurement of PT,PTT Done by CoaDATA4004.

- Two ml of blood was taken on a plain tube (without anticoagulant) for serum separation. The tube was left at room temperature for 30 minutes till coagulation, and then was centrifuged (at $1500 \mathrm{rpm}$ for 15 minutes). The resultant serum was used for clinical chemistry tests: Urea, creatinine, sodium, SGPT SGOT potassium and blood sugar. Done by BT3500.

\section{Biomarker Assay (uKIM)}

uKIM was conducted using SunRed Bio (shanghaichina) immunoassay.The outcome was devided into 2 groups, KI and non-KI group on baseline examination and according to the criteria proposed by AKI network in 2007

\section{Results}

The present study was conducted on 30 critically ill infants (18 of them develop KI and 12 did not develop KI). They were $60 \%$ females and $40 \%$ males . mean weight was $6.1 \pm 2.4 \mathrm{~kg}$. In addition to 20 healthy control subjects of matched age and gender. Gender and weight did not differ significantly between both groups.

Table (1) Comparison of demographic, and anthropometric data of all studied groups.

\begin{tabular}{|c|c|c|c|c|c|c|c|c|c|c|c|}
\hline \multirow{4}{*}{$\begin{array}{l}\text { Female } \\
\text { Male }\end{array}$} & \multirow[b]{3}{*}{$\mathrm{N}, \%$} & \multirow{2}{*}{\multicolumn{2}{|c|}{$\begin{array}{c}\text { Control } \\
\mathbf{N}=\mathbf{2 0}\end{array}$}} & \multicolumn{6}{|c|}{ Critically ill } & \multirow{4}{*}{$\begin{array}{l}\mathbf{P}^{1} \\
1^{\mathrm{C}}\end{array}$} & \multirow{4}{*}{$\begin{array}{c}\mathbf{P}^{2} \\
0.736^{\mathrm{C}}\end{array}$} \\
\hline & & & & \multicolumn{2}{|c|}{$\begin{array}{c}\text { All cases } \\
\mathbf{N}=\mathbf{3 0} \\
\end{array}$} & \multicolumn{2}{|c|}{$\begin{array}{c}\begin{array}{c}\text { Without KI } \\
\mathrm{N}=12\end{array} \\
\end{array}$} & \multicolumn{2}{|c|}{$\begin{array}{c}\text { With KI } \\
\text { N=18 } \\
\end{array}$} & & \\
\hline & & 12 & 60 & 18 & 60 & 6 & 54.5 & 12 & 61.5 & & \\
\hline & $\mathrm{N}, \%$ & 8 & 40 & 12 & 40 & 5 & 45.5 & 6 & 38.5 & & \\
\hline & mean $\pm \mathrm{SD}$ & 7 & 2.1 & 6 & 1.6 & 6.4 & 1.8 & 6.9 & 1.6 & $0.423^{t}$ & $0.747^{t}$ \\
\hline Age (months) & Min-max & 35 & 41 & 34 & 40 & 35 & 40 & 34 & 40 & $0.423^{3}$ & $0.74 t^{3}$ \\
\hline Lenoth $(\mathrm{cm})$ & mean $\pm \mathrm{SD}$ & 42.7 & 14.1 & 48.8 & 1.9 & 49 & 2 & 48.9 & 1.8 & $0066^{t}$ & $0.705^{t}$ \\
\hline Length $(\mathrm{cm})$ & Min-max & 1.7 & 52 & 45.1 & 51.5 & 45.8 & 51.5 & 45.1 & 51.5 & $0.522^{t}$ & $0955^{t}$ \\
\hline
\end{tabular}

$\mathrm{SD}$, standard deviation; min, minimum; max, maximum; KI, kidney injury; $t$, $\mathrm{t}$ test; $\mathrm{C}$, chi square; $\mathrm{p} 1$, comparison between cases and control; p2, comparison between critically ill with and without AKI.

Table (2) Comparison of hematologic investigations at diagnosis of all studied groups.

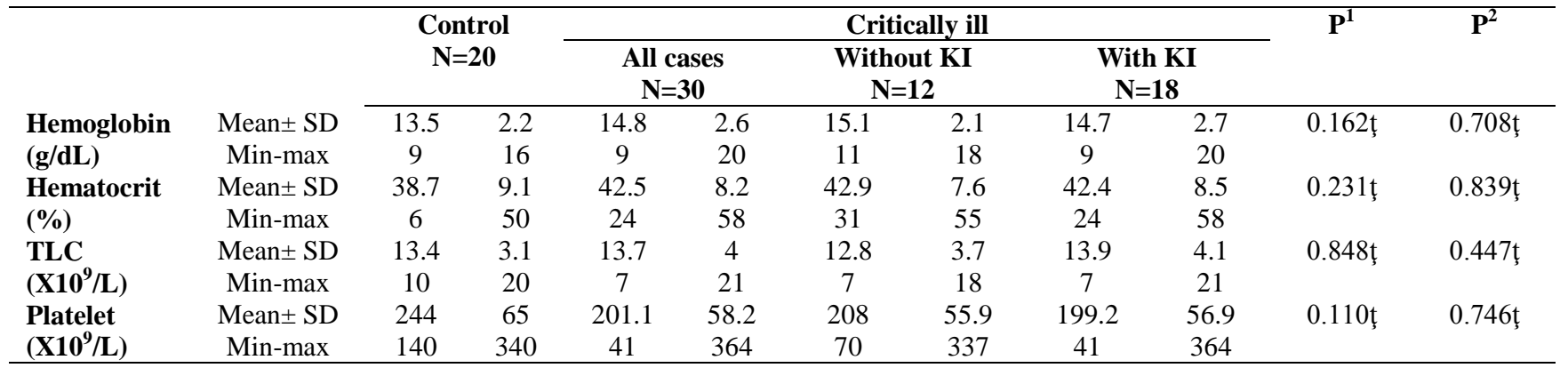

$\mathrm{SD}$, standard deviation; min, minimum; max, maximum; KI, kidney injury; ţ, t test; p1, comparison between cases and control; $\mathrm{p} 2$, comparison between critically ill with and without AKI.

Table (3) Comparison of routine investigations between first and second samples in studied critically ill infants. 


\begin{tabular}{|c|c|c|c|c|c|c|}
\hline & & \multicolumn{4}{|c|}{$\begin{array}{c}\text { critically ill infants } \\
\qquad \mathbf{N}=\mathbf{3 0}\end{array}$} & \multirow[t]{2}{*}{$\mathbf{P}$} \\
\hline & & Firs & iple & Seco & nple & \\
\hline \multirow{2}{*}{ Hemoglobin (g/dL) } & Mean \pm SD & 14.8 & 2.6 & 13.9 & 2.2 & \multirow{2}{*}{0.071} \\
\hline & Min-max & 9 & 20 & 8 & 21 & \\
\hline \multirow{2}{*}{ Hematocrit (\%) } & Mean \pm SD & 42.5 & 8.2 & 39.3 & 6.7 & \multirow{2}{*}{0.093} \\
\hline & Min-max & 24 & 58 & 25 & 62 & \\
\hline \multirow{2}{*}{ TLC $\left(\mathrm{X10}^{9} / \mathrm{L}\right)$} & Mean \pm SD & 13.7 & 4 & 12.9 & 3.1 & \multirow{2}{*}{0.101} \\
\hline & Min-max & 7 & 21 & 5 & 17 & \\
\hline \multirow{2}{*}{ Platelet $\left(\mathrm{X10}^{9} / \mathrm{L}\right)$} & Mean \pm SD & 201.1 & 58.2 & 196.9 & 49.6 & \multirow{2}{*}{0.634} \\
\hline & Min-max & 41 & 364 & 29 & 349 & \\
\hline \multirow{2}{*}{ Urea (mg/dL) } & Mean \pm SD & 32.8 & 8.9 & 42.9 & 12.3 & \multirow{2}{*}{$<0.001$} \\
\hline & Min-max & 14 & 83 & 20 & 101 & \\
\hline \multirow{3}{*}{$\begin{array}{l}\text { Serum Creatinine } \\
(\mathbf{m g} / \mathbf{d L})\end{array}$} & Mean \pm SD & 0.5 & 0.1 & 1.1 & 0.5 & \multirow{3}{*}{0.001} \\
\hline & Min-max & 0.3 & 0.9 & 0.4 & 2.5 & \\
\hline & Min-max & 22.9 & 70.25 & 7.6 & 49 & \\
\hline \multirow{2}{*}{$\mathbf{N a}$} & Mean \pm SD & 140.2 & 7 & 140.2 & 5.8 & \multirow{2}{*}{0.951} \\
\hline & Min-max & 130 & 154 & 132 & 156 & \\
\hline \multirow{2}{*}{$\mathbf{K}$} & Mean \pm SD & 3.8 & 0.5 & 4 & 0.7 & \multirow{2}{*}{0.106} \\
\hline & Min-max & 2.9 & 5 & 2.4 & 6 & \\
\hline
\end{tabular}

$\mathrm{SD}$, standard deviation; min, minimum; max, maximum. Numerical data were tested using paired sample $\mathrm{t}$ test.

Table (4) Correlation of KIM level with other renal function tests in all critically ill neonates.

\begin{tabular}{|c|c|c|c|c|}
\hline & \multicolumn{4}{|c|}{$\begin{array}{c}\text { critically ill infants } \\
\mathrm{N}=\mathbf{3 0}\end{array}$} \\
\hline & \multicolumn{4}{|c|}{ KIM } \\
\hline & \multicolumn{2}{|c|}{ First sample } & \multicolumn{2}{|c|}{ Second sample } \\
\hline & $\mathbf{r}$ & $\mathbf{p}$ & $\mathbf{r}$ & $\mathbf{p}$ \\
\hline Serum creatinine & 0.322 & 0.054 & 0.797 & $<0.001$ \\
\hline Urea & 0.228 & 0.320 & -0.063 & 0.663 \\
\hline
\end{tabular}

Pearson correlation.

\section{Discussion}

Our study revealed no significant difference between groups of the study regarding age, length, and weight with predominance of female sex.

S.A. Walters et al. [11], found that, there was no statistical significant difference between the studied groups regarding age and sex which was in agreement with our study. Both studies aimed to evaluate the role of kidney injury molecule (KIM) as an early marker for kidney injury (KI) in critically ill infants.

A.I. Lim et al. [10], found in their study that there was no significant difference between both sexes in the group of KI which disagree with our results.

Our study revealed non-significant change in the CBC in $\mathrm{KI}$ and patients without KI. And renal functions in our study revealed no significant change between KI patients and patients without KI in the first sample while significant change in creatinine level in second sample.

N.A. Abdelaal et al. [12], in their study found that in the first sample the mean of serum creatinine values were not significantly different between infants with KI compared with infants with no KI and controls, and in the second sample there was a significant increase in serum creatinine in infants with KI when compared with non KI and controls which was in agreement with our results.
Serum creatinine has a delay in rise of as much as $48 \mathrm{~h}$ after the injury which was in agreement with our study [14].

This disagreed wit., B.T. Workeneh [15] who reported that there is no statistically significant difference between patients who developed KI and those who did not develop $\mathrm{KI}$ at $48 \mathrm{~h}$ regarding serum creatinine.

CRP was significantly elevated in critically ill patients with no significant change in $\mathrm{Na}, \mathrm{K}, \mathrm{pH}$ between them and control group or between patients with $\mathrm{KI}$ and those without $\mathrm{KI}$.

M.Y. Park et al. [16], in their study found that CRP as a continuous variable was found to be associated with KI which was in agreement with our results Also, Shacham and his coworkers, showed in their studies that studies reported CRP was a significant predictor for KI and clinical outcomes in cardiac surgery which run in line with our results [11].

In our study we found that there was no difference in blood culture in KI or non-KI groups.

Park and his colleagues, found in their study that there was no difference in blood culture or other hematological values in patients of KI which was in agreement with our results [16].

In our study there was a positive correlation between KI and KIM. 
A.I. Lim et al. [10] concluded in their study that urinary KIM levels were significantly elevated within few hours after kidney damage which was in agreement with our study.

\section{Conclusion}

$\mathrm{KIM}$ is a sensitive urinary biomarker in early detection of $\mathrm{KI}$ in infants.

\section{References}

[1] R.L.Mehta, J.A Kellum, S.V Shah, Acute kidney injury network: Report of an initiative to improve outcomes in acute kidney injury. Crit. Care, Vol.11, PP 31-39.2007.

[2] A.B. Libório, K.M.Branco, T.D.Melo, Acute kidney injury in neonates: from urine output to new biomarkers. BioMed research international,VOL.2(14),PP321-328.2014.

[3] M.S.Smertka and J.A.Chudek, Using NGAL as an early diagnostic test of acute kidney injury," Renal Failure, vol. 34, pp 130-133.2012.

[4] W.H. Huo, K.P. Zhang , Z.M. Nie, Kidney injury molecule-1 (KIM-1): a novel kidney- specific injury molecule playing potential double-edged functions in kidney injury. Transplatation Reviews,vol. 24,pp 143146.2010.

[5] I.M. Paramastuty, K.H.Soebandiyah , B.F.Basuki, Urinary Kidney Injury Molecule-1 (KIM-1) in Early Diagnosis of Acute Kidney Injury in Pediatric Critically Ill, Journal Of Tropical Life Science ,vol.6(1),pp2834.2016.

[6] N.A. Abdelaal, S.A. Shalaby, A.K. Khashana, Serum cystatin $\mathrm{C}$ as an earlier predictor of acute kidney injury than serum creatinine in preterm neonates with respiratory distress syndrome. Saudi J Kidney Dis Transpl ,vol.28(5),pp 1003-1014.2017.

[7] F.E Raluca, G.K. Bianca,V.A Mihalay, Plasma neutrophil gelatinase associated lipocalin - early biomarker for acute kidney injury in critically ill patients. Crit Care Med,vol.1,pp154-161.2015.

[8] I.M. Boghdady, M.M. ELNaggar, M.M Emara, Kidney injury molecule-1 as an early marker for acute kidney injury in critically ill patients. Menoufia Medical Journal,vol. 26,pp 98-104. [2013]:

[9] D.G. Youssef, H.L. Abd-Elrahman, M.M Shehab, Incidence of Acute Kidney Injury in the Neonatal Intensive Care Unit. Saudi J Kidney Dis Transpl,vol.26(1),pp67-72. 2015.

[10] A.I. Lim, S.C. Tang, K.N. Lai, Kidney injury molecule 1 , more than just an injury marker of tubular epithelial cells? J Cell Physiol ,vol.228,pp917-924. 2013.

[11] S.A. Walters, C.B. Porter and B.D. Brophy, Dialysis and pediatric acute kidney injury: choice of renal support modality. Pediatr Nephrol,vol. 24(1),pp 3748.2009.

[12] N.A. Abdelaal, S.A. Shalaby, A.K. Khashana, Serum cystatin $\mathrm{C}$ as an earlier predictor of acute kidney injury than serum creatinine in preterm neonates with respiratory distress syndrome. Saudi J Kidney Dis Transpl 28(5): 1003-1014. 2016.

[13] J.G. Jetton and D.J. Askenazi, Update on acute kidney injury in the neonate. Curr Opin Pediatr,pp 24(2),vol. 191-196.2012.

[14] J.G.Jetton, E.T.Rhone, M.W. Harer, Diagnosis and Treatment of Acute Kidney Injury in Pediatrics Curr Treat Options Peds ,vol.2,pp56-68.2016.

[15]B.T. Workeneh, Acute renal failure .http:// emedicine .medscape $\quad$.com/article /243492overview,vol.25(2),pp47-62 .2011.

[16] M.Y. Park, S.J. Choi, Effect of treatment on urinary kidney injury molecule-1 in IgA nephropathy. BMC Nephrol,vol.14(3), pp 139-146.2016. 